\title{
Mindfulness as a General Ingredient of SuCCeSSFul Psychotherapy SYNOPSIS
}

In this chapter I present a psychological conceptualization of mindfulness based on constructs in common therapeutic parlance. Taking a functional approach based on the skills and recognitions patients gain from the exercises commonly used in mindfulness training and avoiding exotic and cryptic language, it makes apparent both the commonality mindfulness has with modalities therapists will be already using in their clinical practice and the ways in which it may add something new and therapeutically useful. It also describes the evolutionary pressures that have shaped the biological imperatives driving the default movements of attention that result in day to day experience being experienced as less than pleasant; defaults that result in both the need for, and the challenge of cultivating mindfulness. So, while the instructions and narrative within which these principles are introduced into therapy will need to be adapted to the patient's background and circumstances, an understanding and grounding in the principles enables the therapist both to skillfully make these adaptations to the training exercises and to make them immediately sensible to the patient, including the challenges they will meet in getting started. 


\section{Mindfulness as a General Ingredient of SuCCeSSFul Psychotherapy}

\section{The Common Goal Mindfulness Training has with Psychotherapy}

While a complete list of psychotherapy's goals, and the means therapists have employed to facilitate these would be long and diverse, the over-arching themes are increasing quality of life and reducing emotional suffering; goals that are shared by all Buddhist schools of thought, even as they vary in their approaches and practices. But while Buddhism and psychotherapy have broadly similar ends, and even share some techniques to foster beneficial change, historically their approaches stood in contrast. Western therapeutic systems focused principally on modifying cognitions and behavior and/or developing an intellectual understanding of the dynamics of the internal narrative. Buddhist approaches, while including the standard religious admonishments to ethical behavior and positive cognitions in their systematic path, offered in addition, exercises to cultivate insight into the moment to moment construction of personal identity in the mind and the degree of suffering/wellbeing resulting from patterns of responding to these constructions. Mindfulness, and the range of mind-training exercises designed to facilitate it, occupies an important place in the development of this experiential insight.

Recognizing the overlapping goals of Buddhist and Western approaches, and particularly the therapeutic opportunities represented by the Buddhist mind training exercises, mindfulness instruction was introduced into clinical settings, principally through the work of Kabat-Zinn (Kabat-Zinn, 1982). Subsequent randomized trials have provided solid evidence for the effectiveness of mindfulness training in reducing stress and distress in both clinical (Hofmann, Sawyer, Witt, \& Oh, 2010), and non-clinical populations (Chiesa \& Serretti, 2009; Fjorback, Arendt, Ørnbøl, Fink, \& Walach, 2011). The positive benefits that relate directly to the goals of psychotherapy include: increased subjective well-being, reduced psychological symptoms and 
emotional reactivity, improved behavioral regulation, and improved interpersonal coping skills (Davis \& Hayes, 2011; Keng, Smoski, \& Robins, 2011). Studies of the mechanisms of change indicate that increases in mindfulness mediate and precede (Baer, 2009; Bränström, Kvillemo, Brandberg, \& Moskowitz, 2010; Carmody, Baer, Lykins, \& Olendzki, 2009; Kuyken et al., 2010) reductions in distress (Baer, Carmody, \& Hunsinger, 2012), and longer term trials show that improvements in well-being from the training are enduring when compared to an educational control program (Pbert et al., 2012).

This range of benefits to psychological well-being (Hofmann et al., 2010) has led to mindfulness training being creatively adapted to Western therapeutic models and successfully integrated into a growing variety of clinical treatment modalities, both exclusively as in Mindfulness-Based Stress Reduction (MBSR), and in parallel with practices such as selfreflection, journal writing, skills training, affect tolerance and reframing (Sanders, 2010) in programs such as Dialectical Behavior Therapy (DBT) (Linehan, 1993), Mindfulness-Based Cognitive Therapy (MBCT) (Teasdale, Segal, \& Williams, 1995), and Acceptance and Commitment Therapy (ACT) (Hayes, Strosahl, \& Wilson, 1999). Trials of each of these programs have shown that the training does indeed improve outcomes in their clinical populations (Vøllestad, Nielsen, \& Nielsen, 2011). Reports of studies of the effect of mindfulness in the more traditional psychotherapeutic process have also proliferated in recent years, including its role in the therapeutic encounter (Davis \& Hayes, 2011). While the evidence in this area is less solid, mindfulness does appear to contribute to therapists' self-care (Christopher et al., 2011) and to make for more compassionate and empathetic therapists, although it does not necessarily translate into their having better therapy outcomes (Davis \& Hayes, 2011). 


\section{The Challenges of Integrating Mindfulness into Clinical Settings and Empirical Systems}

Even as there is broad acceptance of the clinical utility of mindfulness, there remain a number of knowledge gaps that are important to fill if it is to find more widespread integration into psychotherapy. These include both the lack of a testable theoretical model to serve as an integrative foundation for comparative studies (Sedlmeier et al., 2012) and, related to this, significant variation in the literature on how the construct is best understood (Chiesa \& Malinowski, 2011; Langer \& Moldoveanu, 2000; Ludwig \& Kabat-Zinn, 2008) and how to determine valid criterion references for self-report measures of mindfulness (Davidson, 2010). Disagreements extend even to whether it is possible to conceptually define and measure mindfulness without loss of its essential nature; asserting that it must be experientially understood within the larger Buddhist framework from which it is derived (Grossman, 2008; Harrington \& Pickles, 2009). More particular to the process of integrating mindfulness into psychotherapy is the dearth of evidence related to both the minimum amount of training and practice time required for patients to derive benefits from mindfulness training (Carmody \& Baer, 2009), and the amount of training and experience in mindfulness practice therapists need to have in order to be able to represent and integrate it 'correctly' (Davis \& Hayes, 2011).

There are a number of reasons that such differences and knowledge gaps are to be expected in this field: First, the construct of mindfulness is extracted from a larger and more comprehensive Buddhist religious system. In the original Pali texts 'samma-sati' is one of eight factors to be cultivated in order to understand the momentary creation of mental states, and to reduce life's suffering. 'Mindfulness' has come to be the accepted translation of 'sati', and 'samma-sati' is generally understood as skillful mindfulness. Sati can also be understood as awareness however, and in a clinical context 'skillful awareness' may be a preferable term to 
mindfulness because awareness is a mental function within patients' existing realm of experience, and so immediately conceptually accessible. It also avoids the possible confusion that can arise by objectifying a term like 'mindful' that has a pre-existing conceptual meaning in Western literature.

A second reason for differences is the wide variation that exists among different Buddhist traditions and teachers in the understanding of mindfulness (sati), and how it is most skillfully cultivated and integrated into the broader system. In Soto Zen traditions for example, great emphasis is placed on directing effort to maintain correct posture during formal meditation (zazen) and typically refraining from abstract instructions for the cultivation of mindfulness. That it is something that is cultivated through awareness of ones actions and surroundings. In the Theravada South Asian traditions on the other hand, formal meditation involves a more wideranging exploration of mental activity, and with systematic cultivation of the awareness of this and other sensory experience in daily life.

Finally, and perhaps most significantly, important variations in emphases and understanding are bound to occur when an approach to the cultivation of well-being moves from conceptions of suffering in the traditional Eastern cultures the system developed within, into the enshrined Western pursuit of happiness, and the diversity of cultural and personal aspirations associated with well-being in a market society. In the Buddhism of traditional Eastern cultures an accepted truth was that suffering was to be expected, not escaped from, and efforts to do so will lead only to further suffering. It should be kept in mind also that these were typically socially static societies when compared with the aspirational culture we are socialized into, in which ubiquitous advertising offers the promise of escape from our circumstances. 
Even so, most descriptions of mindfulness in the clinical literature have used some variation on Kabat-Zinn's definition of paying attention in a particular way: on purpose, in the present moment, and non-judgmentally (Kabat-Zinn, 1994; Shapiro, Carlson, Astin, \& Freedman, 2006). While such a description is intriguing as to what may follow by way of its cultivation, it is unlikely on the face of it to mean much to most clients and patients not already familiar with mindfulness practice. At worst, it may be perceived as sufficiently cryptic, challenging, and inaccessible to discourage further exploration. In this regard, patients are often asked to suspend their need for a conceptual understanding in favour of grasping it through experience with one of the training exercises.

Avoiding the Definition Problem: Understanding Mindfulness through the Training Exercises

To weave a way through these differences in understanding, and to make the construct more immediately accessible than the usual clinical definition, I describe in this chapter a conceptual model that draws upon forty-odd years of personal practice in the three major Buddhist traditions; professional experience as a therapist; clinical research studying the outcomes and mechanisms of mindfulness training; and from teaching mindfulness to patients and clinicians. It is based on the skills taught in clinical mindfulness training exercises, and describes how the exercises support the experiential recognition of three features of mental activity not normally discerned, and how this recognition affects the individual's lived experience. As such it revolves around facility in the use of attention, together with recognizing components of mental experience and their conditioned associations that the attentional facility and increased awareness make possible.

In subsequent sections I expand on and discuss the features of the model concretely, including its usefulness in psychotherapy by providing a parsimonious and accessible conceptual 
framework for presenting and discussing mindfulness with patients and clients (Carmody \& Baer, 2009). But briefly, and rather abstractly, they can be described as follows:

1) Our everyday experience, while apparently seamless, is in fact constructed from three phenomenological components which form associational cycles. Those components are: thoughts/images, impressions arriving through the senses, and the pleasant/unpleasant feeling tone associated with these. The richness of our experience; memory, imagination and emotion, are the result of the symphonic interplay of these fundamental elements.

2) Because attention is normally preoccupied with the content of these components, they go unrecognized, thereby sustaining their associational cycles. If it is a thought for example, it is occupied with what the thought is about, or means. With training, these components can be recognized as events (mind objects) occurring in the field of awareness, thereby disrupting the cycle.

3) Attention is adapted to highlight novelty and possibilities for/threats to fulfillment of needs (including safety) but the movement of attention itself is not normally noticed. Rather, the object of attention is noticed, and arousal levels and affects follow the degree of threat/delight represented by that content.

\section{The Utility of a Functional, Evolutionary Approach}

While these features become evident upon reflection, in everyday life their rapidity and automaticity results in experience being perceived as seamless, and so presenting to the patient no apparent opening for some measure of control in the face of distress. This perception results in a sense of powerlessness that exacerbates the stress/distress. The relatively simple mindfulness training exercises (meditations) are designed to facilitate recognition of these three features in everyday experience by developing self-regulation of attention, and cultivating curiousity about, 
and observation of, internal experience. Acquisition of this learning represents a helpful resource for patients to approach the ubiquity of everyday felt experience, and represents an important feature of the clinical utility and therapeutic value of mindfulness (Teasdale et al., 2002). This functional model has a number of advantages in the psychotherapeutic setting for both therapists and patients.

First, psychotherapy, like mindfulness, relies on a certain kind of introspection grounded in the phenomenology of perception. By explicating the qualities of attending to experience that are embedded in mindfulness training exercises, and the effect those can be expected to have on the individual's felt experience, the model makes already familiar psychological processes central to the explanation rather than lab-based neural and biological processes. Second, by using constructs already familiar to both therapists and their clients, it provides a relatively simple conceptual framework that can be individually adapted both to introduce mindfulness to patients in psychotherapy who are naïve to it, and used as a basis for discussing mindfulness in the ongoing therapeutic process. Also, taking it out of the commonly used descriptions and customary mindfulness meditation language avoids the definition problem, and makes mindfulness seem less perplexing and more conceptually straightforward and accessible to patients. Third, it reveals the elements of mindfulness training that have been employed in systems such as cognitive therapy for many years to make features of internal experience accessible to patients. As such, it provides a conceptually unifying foundation that shows both the common ground, and the contrast, mindfulness has with what patients are already learning in therapy.

Lastly, an evolutionary explanation for the stubborn default attending mechanisms that patients encounter when first attempting the mindfulness attention exercises reveals an inherent, 
if dysfunctional, intelligence in those patterns adapted for survival and reproductive success. An appreciation of the adaptive function of this mechanism can help patients to better understand and contextualize the frustrations they encounter, and that often test their resolve to persist in endeavouring to make changes, than the somewhat more pejorative craving, aversion/clinging, attachment explanations derived from Buddhist conceptualizations.

\section{The Three Principles of the Functional Conceptual Model}

The following sections develop and explain these features and illustrate their role in clinical outcomes.

\section{FIRST PRINCIPLE}

Our apparently seamless experience is constructed from a limited number of components (thoughts/images, sensations, and their pleasant/unpleasant feeling tone) which form associational cycles. The richness of experience including memory, imagination and emotion are symphonies of these fundamental elements.

This three-way network linking related mental components in an automatic and unconscious way to form cycles that are experienced as distress is described also by Damasio (Damasio, 2003). In these cycles, a thought/image gives rise to an associated bodily sensation and feeling tone which through associative patterns of memory gives rise to more thoughts related to the sensations and feelings. The cycles can begin with any of the components, but forming and re-forming very rapidly outside of awareness in daily life, the associations are not readily apparent.

Attention is central to the recognition of this principle for two reasons: First, arousal levels follow the object of attention. Thus, when attention is on the content of a sequence of associated fearful thoughts, sensations of constriction, and unpleasant feeling tone, then the 
body's arousal level follows. Second, when attention is not intentionally directed/regulated it can become fixated on a particular sequence, forming a relatively closed loop that maintains the automatic cycle experienced as distress. Anxiety, for example, results when the attention becomes fixated on a fear-related cycle of components. This is illustrated in Figure 1. Depending at least partly upon temperament, some patients will report the distress of this cycle in terms of feeling tone ('I feel bad'), while others will report the cognition component ('I'm worried'). Still others will be more aware of the sensations ('I feel tense').

\section{[Figure 1 here]}

The First Principle in Mindfulness Practice: Conscious Redirection of Attention Affects the Cycle of Arousal/Distress

As I describe in the following section, an important function of the beginning mindfulness exercises is to support patients in learning to discriminate between thoughts, sensations, and their feeling tone. In association with that learning, the recognition that their attention is fixated or compelled by a cycle of associations that is creating distress, opens an opportunity to redirect attention to some other object available to experience that is not being noticed. Commonly used to this end are the sensations associated with respiration; sensations that are arousal-neutral for most people. When attention is directed toward them, the reduced arousal attendant upon an affect-neutral sensation [mental object] naturally follows.

Breath-related sensations have the added clinical utility of being immediately and continually available to patients as an attentional object, and as such, provide an ideal means for invisibly reducing distress and lowering arousal levels in the course of events in everyday life. In Figure 2, the closed cycle resulting in the experience of distress illustrated in Figure 1, is opened to the possibility of change as the patient learns to discriminate between the components, and 
recalls that the sensations of breathing are an arousal-neutral mental object available to their attention.

\section{[Figure 2 here]}

When, as in Figure 2, attention is re-directed towards the sensations of breathing, the cycle of associations that were maintaining distress are interrupted, with accompanying change in affect, and reduced arousal. The principle is exemplified in the instructions for beginning mindfulness practitioners to deliberately redirect their attention to the sensations of respiration (chosen mental object - neutral stimulus) in the face of distressing thoughts, sensations or emotions.

Attention invariably wanders away from the breath sensations for the reasons outlined in principle three, but as long as it is kept on, or repeatedly re-directed back to the breath, arousal and the affect attendant upon a neutral sensation naturally follow. Facility in the use of attention in this way, together with the capacity to discriminate between the components of experience, provides an opportunity for less emotional reactivity to symptoms in the midst of other activities, and a greater sense of control and confidence in dealing with distress. In mindfulness training for depression for example, the focused attention required to sustain a negative stream of thought (with its attendant distress) is diverted, preventing its escalation into ruminative patterns which in turn can lead to increases in ongoing negative psychological states and mental distress (Teasdale et al., 1995; Teasdale et al., 2000).

This strategy can also account for the clinical benefits from mindfulness treatments for anxiety (Kabat-Zinn et al., 1992; Patel, Carmody, \& Simpson, 2007). These attention regulation processes may also account for at least some of the demonstrated reductions in psychological distress from participation in other mind-body training programs (Bertisch, Wee, Phillips, \& 
McCarthy, 2009; Manzoni, Pagnini, Castelnuovo, \& Molinari, 2008) which entail some measure of attention regulation to an arousal neutral or affect-positive mind object such as; focusing on breathing exercises, symptom monitoring, guided imagery, prayer, mantra, and the focus on bodily sensations in progressive muscle relaxation, tai chi, and yoga.

\section{SECOND PRINCIPLE}

The components of experience (thoughts/images, sensations, and their pleasant/unpleasant feeling tone) are referred to as mind objects in some Buddhist training traditions, and to be recognized as events occurring in the field of awareness. In current therapeutic parlance this skill is often referred to as reperceiving, or metacognitive awareness (Safran \& Segal, 1990; Teasdale et al., 2002).

The therapeutic challenge is that attention is normally and naturally preoccupied with the content of the components (what they are about/mean) thereby sustaining their associational cycles and attendant distress. So, having learned to distinguish between thoughts and the attendant sensations and feelings, mindfulness training instructions often include the activity of labeling the component ('this is a thought") to support this perceptual shift. With the recognition that the mental components are events occurring in the mind, and can be perceived as such, the attention on their content required to maintain the cycle of distress is diluted. The difference between these two orientations is illustrated in Figure 3.

\section{[Figure 3 here]}

\section{Evidence for the Importance of the First Two Principles in Mindfulness Training}

Several lines of evidence support the importance of attention and reperceiving/metacognitive awareness in the reductions in distress associated with mindfulness training. Self-reports of patients who have completed a mindfulness training program show that 
attentional redirection is one of the most important skills they continue to use in coping with their symptoms and to increase their well-being. In a four-year follow-up study (Kabat-Zinn, Lipworth, Burney, \& Sellers, 1987) of participants in an MBSR program, nearly all reported using redirection of attention to the sensations of breathing to some extent in their daily life situations, and 74-94\% reported it to be moderately, or very useful, in coping successfully with stressful situations. Similarly, in a study of MBSR for women with severe hot flashes (Carmody, Crawford, \& Churchill, 2006) found clinically significant improvements in menopause-related quality of life, perceived stress, and sleep quality, exit interviews showed that most women reported using redirection of attention to the sensations of the breath to help them cope in the face of their hot flashes and night sweats. In this way they developed a greater sense of control and confidence in dealing with their symptoms.

The importance of re-perceiving in the reductions in distress from mindfulness training was shown by Teasdale and colleagues, who found that it was a central component in reducing relapse in patients with major depressive disorder (Teasdale, 1999; Teasdale et al., 2002). In addition, an observational study of mechanisms of change over the course of an eight-week MBSR program found large effect size increases in re-perceiving (Carmody et al., 2009); larger than the increases in mindfulness.

These self-reports showing the importance of attention regulation to well-being are supported by laboratory studies of attentional processes that relate directly to mindfulness practice instructions. Jha, and others, have found improved volitional orienting of attention with mindfulness training that appeared to be associated with the extent of mindfulness practice (Chan \& Woollacott, 2007; Jha, Krompinger, \& Baime, 2007). In addition, Valentine and colleagues (Valentine \& Sweet, 1999) found that mindfulness practitioners had superior performance on a 
sustained attention task (Wilkins counting test), especially when the stimulus was unexpected, and performance was related to length of experience with practice.

Mindfulness practice also supports the allocation of attentional resources. In the phenomenon known as attentional blink, subjects presented with two targets (pictures or numbers) imbedded in a rapid series of distractor stimuli (non-target numbers or pictures) tend to miss the second stimulus if it is presented within a half second of the first. This is thought to occur because attentional resources are limited, and if those resources are consumed in processing the first stimulus, the second stimulus is missed. Further, Slagter and colleagues (Slagter et al., 2007) found that the more experienced mindfulness meditation practitioners exhibited a smaller attentional blink effect and attributed this to their more efficient allocation of attentional resources resulting from the training. In other words, their attention was less caught up by the first stimulus and available for a different stimulus.

Finally, building upon the findings of Ellenbogen and colleagues (Ellenbogen, Schwartzman, Stewart, \& Walker, 2006), that subjects trained to deliberately direct attention to the neutral word of a neutral-negative word pair reported less negative affect to a subsequent mental stressor, Ortner and colleagues (Ortner, Kilner, \& Zelazo, 2007) found that mindfulness training was associated with more rapid disengagement from emotionally provocative stimuli.

\section{THIRD PRINCIPLE}

Attention highlights in awareness selected features of available experience, and is adapted to highlight novelty, and objects perceived even indirectly, as leading to the satisfaction of, or threats to the fulfillment of, needs and longings. The movement of attention itself is not normally noticed however, and learning to regulate attention to facilitate the process of recognition of these principles presents several obstacles. First, evolutionary processes have 
resulted in default movements of attention that are adapted to serve survival and reproduction. Second, this default movement of attention itself is not normally noticed; rather the content of the object that the moving attention is highlighting is noticed, together with the arousal levels and affect tone associated with the degree of threat/delight represented by that content. This automatic process can result in delight in moments when things are going well, such as a new relationship, or opportunity. More commonly however, attention is in its adapted role of monitoring for threats to need fulfillment.

Self-Regulation of Attention is Important to Wellbeing, But Getting Started in the Face of Distress is Challenging

As long ago as the $19^{\text {th }}$ century William James famously wrote that 'my experience is what I agree to attend to' (James, 1890). The centrality James gave to attention in shaping our experience continues to find support in a number of therapeutic systems that address selfregulation (Baumeister \& Heatherton, 1996; Kirschenbaum, 1987). Further, an assumed capacity for attention self-regulation is contained in the familiar encouragement given to children to 'pay attention' when learning something for which they have no immediate affinity. Nevertheless, although James' declaration is conceptually straightforward, and intuitively apparent, children, and patients are not normally encouraged or taught to attend to attention itself. Moreover, James' own ongoing struggle with depression in his life points to the challenge of putting attention regulation into practice in the face of psychological difficulties and distress. Even a century later, psychotherapeutic systems had not developed systematic methods of cultivating attentional selfregulation as a generic capacity in the service of wellbeing; a deficiency that was successfully addressed in the mindfulness training exercises derived from Buddhist practices. 
Nevertheless, while these exercises build a foundation for the well-documented opportunities for increased self-regulation and well-being, they require some practice (Carmody \& Baer, 2008), and patients commonly report some level of difficulty in learning to regulate attention in this way (Segal, Williams, \& Teasdale, 2002). When first beginning the foundational mindfulness exercise of attending to the sensations of respiration, the typical report is along the lines of 'Gosh, I never realized how much my mind wanders - it seems to have a mind of its own'. A typical response from many instructors is to reassure the trainee that this initial frustration is to be expected, that everyone experiences the same challenge, and encouragement to persist in the face of it. A more meaningful response may be to give patients a conceptual introduction that clarifies some of the embedded mental dynamics they face in getting started, and framed within the question of why this simple attempt at attention regulation should be associated with any difficulty at all.

How Evolutionary Pressures Have Resulted in Attentional Defaults: This Biological Imperative Makes Attentional Self-Regulation Challenging to Cultivate

In a way the mind does have 'a mind of its own', and the reasons this seemingly straightforward attentional regulation activity, so foundational to well-being, should be such a challenge are often not addressed in mindfulness instruction. As stated above, the instructor may respond with the assurance that everyone has difficulty, as indeed they do, or resort to a traditional Buddhist explanation that the mind is 'clinging' or 'attached', but such explanations are thin conceptual gruel and do not place the patient's difficulty in a readily understandable framework. An evolutionary approach provides a recognizable explanatory frame that lets beginners appreciate that this feature of their mind is not an enemy to their desire for greater 
well-being, but an important, if sometimes less than functional feature, of a mental ecology evolved to meet their most basic needs of survival and reproductive success.

Attention's immediate, automatic and pre-cognitive movement toward physical threats to safety has obvious survival value. Furthermore, its universality and automaticity suggest an adapted neural mechanism responsible for it. Compared with our remote ancestors however, our need for the necessary sense-based scanning of the environment for acute physical threats has become minimal. The relative physical security of modern life means that when not deliberately or sensationally directed elsewhere, attention now largely monitors for threats and opportunities for the fulfillment of other needs, particularly those for power, status, and relationship; needs that require considerable cognitive activity in the form of planning and strategizing. This is apparent in the way attention repeatedly favors the cognitive accompaniment of this monitoring which is subjectively experienced as the all too familiar personal narrative. Attention defaults to this internal monologue of unending commentary and evaluation in preference to the broader landscape of sensory experience available in the immediate physical surroundings, or to routine bodily sensations.

Given the essentially social nature of human life, this default movement of attention should not be unexpected. As physical threats diminish, there is survival and reproductive value in attention now defaulting to a mental process that weaves together a narrative related to appraising possible threats to relationship, status, and power. And given the needs this internal monologue serves, it typically manifests as preoccupation with worries about family, work, money etc., or to plans to move toward satisfying these and other needs and longings, together with imagined threats and allies in their fulfillment. Because the movement of attention itself typically happens largely outside of conscious awareness, we take this pre-occupation for 
granted; referring to it sometimes as 'wandering mind' or more formally as 'stimulusindependent thought' (Buckner, Andrews Hanna, \& Schacter, 2008). And when attention is left to this default state (i.e. when it is not actively directed), this cycle can be self-sustaining, with felt experience being dictated by whatever is the current concern.

The phenomenological dilemma is that even as this default functions to protect and move us to the satisfaction of important needs, its recurrent orientation toward threat monitoring and solutions means that it is, by its nature, more or less fear-related. And since arousal levels and downstream physiological processes follow the threat/delight represented by the object of attention, this fixation on forming and re-forming threat-related associational cycles, either from habit or from the present intensity of an experiential component such as pain, results in some elevated level of arousal. Over time, this attentional default results in everyday life being experienced as less than pleasant, and has a profound effect upon the development and maintenance of mental suffering. It is the familiar human malaise that Buddhism refers to as the first and second noble truths; that life is characterized by suffering, or stress, resulting from craving and aversion.

It is the felt experience of these adaptive default processes that brings many patients to therapy, and also makes the attention regulation in mindfulness training and other mind-body exercises the challenge that patients almost universally report ('My mind [attention] wanders'; 'I'm bored').

Instructions for Mindfulness Training Exercises are Designed to Facilitate Recognition of These Three Principles.

The initial exercise often used to begin mindfulness training is one now commonly referred to as the body scan; a practice from the Burmese Buddhist tradition. In this exercise 
attention is initially brought to notice the sensations of respiration. Once awareness of these as affect-neutral mind objects always available to attention is established, attention is then moved systematically through all parts of the body. The instruction is just to notice whatever sensations happen to be present in each part, including noticing if no sensation is present. No effort is made to change the sensations, or the pace or depth of the respiration; just noticing whatever sensation happens to be present in that body part, and the feeling tone (pleasant/unpleasant/neutral) associated with it.

Attention sooner or later inevitably wanders to its default objects, typically the internal monologue, or the sensations and feelings related to it. When this wandering is noticed, the instruction is to return the attention to exploring the sensations in the body. If powerful experiences emerge during the process, the breathing sensations are available as arousal-neutral objects to which the attention can be returned.

Once some facility in noticing sensations is established, instruction is extended to noticing cognitions, including any that may be associated with the sensations and feelings. Intrusive cognitions are a good place to start since they are most readily identifiable and labeled as thoughts (reperceiving/meta-awareness). While initially practiced with the body lying or sitting still, these exercises can be extended to being done while moving by practicing them during walking, or stretching as a way of supporting their integration into everyday life.

Some facility in just these relatively simple skills results in reductions in distress for many patients, and with some practice the fluidity of attention that results can create a real possibility for greater freedom. Nevertheless, the amount of training and practice that is required has not been systematically studied (Carmody \& Baer, 2009). Initial assumptions have been based on a typical traditional Buddhist monastic practice period of around forty-five minutes. An 
ongoing time commitment such as that is neither feasible nor desirable for many patients. It may also not be necessary to result in clinical gains; a four-year follow-up study of MBSR participants (Kabat-Zinn et al., 1987) found that many of the post-program clinical gains were maintained even though only thirty percent of the respondents described themselves as 'regular meditators'. And other studies (Arch \& Craske, 2006; Zeidan, Gordon, Merchant, \& Goolkasian, 2010) indicate that instruction and practice can be brief enough to integrate into a typical fifteen minute primary care appointment. The pervasive and ubiquitous cognitions foundational to personal identity that interest committed practitioners are more subtle and challenging to recognize however, and require a particular kind of sustained curiosity that the therapist or patient may, or may not, have.

The field of sensation is the starting place in mindfulness training for a number of reasons. First, in the face of the apparent seamlessness of experience, sensation is readily perceptible and distinguishable for most people. Second, even though it is the realm through which we initially experience delight, in the process of socialization sensation becomes neglected by attention in favour of cognitions, including thoughts experienced as memories and imaginings triggered by the sensations. Third, for most the world of sensation, including the senses of sight and hearing, is the realm through which we connect most immediately, intimately, and satisfyingly with others and the world around us. It is a realm of consensus and sharing that stands in contrast with the cognitively-based internal monologue with which attention is so often pre-occupied, and which is experienced as a place of separation, endless explanation, alienation and worry. Cultivating an interest in attention itself and its movement in this way, reveals to the patient just how much their attention defaults to this internal monologue, subverting sensory life in the process, and the delight and satisfaction that can arise with it. 
It can be seen from these relatively simple instructions that patients have an opportunity to learn and recognize a number of therapeutically valuable things in the process of doing the exercises. These include self-regulation of attention, discriminating sensations from thoughts and feelings, becoming aware of the movements of attention, experiencing how feeling tone follows the object of attention, recognizing that rather than being focused on their content, thoughts can be seen as events in awareness, and rediscovering a neglected realm of experience in which delight and connection are more accessible. The practice of the exercises also predictably increases emotion regulation through exposure and tolerance, and acceptance is implicit in the willingness to engage in these acts of attending and perceiving.

The Role of the Internal Monologue, Its Discontents, and the Complementary Role of Mindfulness in Psychotherapy

While the internal monologue is critical to our functioning in the world, and to the satisfaction of both our needs, and the needs of those we love and care about, the tendency for attention to default to this commentary on the experience arriving through our senses is observably the source of a great deal of trouble. It is characterized by a constant stream of judgments and comparisons as it expresses our beliefs, and attempts among other things, to serve our needs for relationship and status. Being threat-based the attendant arousal results in some level of ongoing suffering, all the while drawing attention away from the world of sensation with its attendant opportunities for delight; a dilemma that brings more than a few into therapy.

And while for some, simply learning that they can re-direct their attention to an arousalneutral or positive mind object at times of stress or distress will be sufficient to their needs and interest, in some circumstances even this will be a challenge. For when important components of the needs-related internal narrative are in conflict, the need for resolution results in ruminative 
patterns that compel attention to their themes. It is worth noting in this regard that some practitioners attempt to use mindfulness to avoid dealing with the monologue's content, themes and conflicts particularly, when these appear too painful or distressing to even approach; attempting to use the principles to dismiss these as just 'events in the mind', and using regular practice in re-direction of attention to maintain some level of mental calm. This avoidance has been referred to as the 'spiritual bypass' and leads to a restricted life in which the practices are maintained as a way of keeping the lid on things. So rather than an opportunity for liberation and greater ease, a kind of attentional vigilance is required as the need for resolution keeps pressing attention back to the conflicting issues.

But as conflicting themes and patterns are recognized in therapy, worked through, and resolved by the development of a more coherent narrative that the patient recognizes is supporting them in moving in a functional way toward satisfaction of the needs they hold most dear, attention is no longer compelled by their content. As a result it becomes more fluid, and the patient can choose which among the constant stream of cognitions and sensations s/he will entertain in the interest of satisfying their larger needs and goals.

Mindfulness can however support the role of psychotherapy in this exposition. For while treatments such as psychodynamic and cognitive psychotherapy effectively improve mood and reduce distress by supporting patients in gaining insight into the themes of the narrative or world view, and challenging and replacing self-defeating cognitions and behaviors with more functional ones, they each to some extent re-arrange the content of mental activity - the mental furniture. Without insight into the way all experience, both functional and dysfunctional, is constructed in the mind from moment to moment, the patient remains vulnerable to a similar malaise resulting from a new set of self-referential negative judgments and comparisons arising 
from some new set of life circumstances. Integrating mindfulness into the therapeutic process by whatever means can provide the patient with the additional wisdom and resilience that is gained through experientially recognizing this fact. Patients and therapists will choose the level of insight they regard as sufficient to address their needs and circumstances, but this integration is used effectively in ACT, MBCT and DBT which each in their own ways support these recognitions to good clinical effect, and inoculate the patient at a more systemic level. 


\section{References}

Arch, J. J., \& Craske, M. G. (2006). Mechanisms of mindfulness: Emotion regulation following a focused breathing induction. Behavior Research and Therapy, 44, pp1849-1858

Baer, R., Carmody, J., \& Hunsinger, M. (2011). Weekly change in mindfulness and perceived stress in a Mindfulness-Based Stress Reduction program. Journal of Clinical Psychology, 68, pp755-765.

Baer, R. A. (2009). Self-Focused attention and mechanisms of change in mindfulness-based treatment. Cognitive behaviour therapy, 38, pp15-20.

Baumeister, R. F., \& Heatherton, T. F. (1996). Self-regulation failure: An overview. Psychological inquiry, 7, pp1-15.

Bertisch, S. M., Wee, C. C., Phillips, R. S., \& McCarthy, E. P. (2009). Alternative mind-body therapies used by adults with medical conditions. Journal of psychosomatic research, 66 , pp511-519.

Bränström, R., Kvillemo, P., Brandberg, Y., \& Moskowitz, J. T. (2010). Self-report mindfulness as a mediator of psychological well-being in a stress reduction intervention for cancer Patients—A randomized study. Annals of Behavioral Medicine, 39, pp151-161.

Buckner, R. L., Andrews Hanna, J. R., \& Schacter, D. L. (2008). The brain's default network. Annals of the New York Academy of Sciences, 1124, pp1-38.

Carmody, J., \& Baer, R. A. (2008). Relationships between mindfulness practice and Levels of mindfulness, medical and psychological symptoms and well-being in a mindfulnessbased stress reduction program. Journal of Behavioral Medicine, 31, pp23-33. 
Carmody, J., \& Baer, R. A. (2009). How long does a Mindfulness-Based Stress Reduction program need to be? A review of class contact hours and effect sizes for psychological distress Journal of Clinical Psychology, 65, pp627-638.

Carmody, J., Baer, R. A., Lykins, E. L. B., \& Olendzki, N. (2009). An empirical study of the mechanisms of mindfulness in a mindfulness-based stress reduction program. Journal of Clinical Psychology, 65, pp613-626.

Carmody, J., Crawford, S., \& Churchill, L. (2006). A pilot study of mindfulness-based stress reduction for hot flashes. Menopause, 13, pp760-769.

Chan, D., \& Woollacott, M. (2007). Effects of level of meditation experience on attentional focus: Is the efficiency of executive or orientation networks improved? Journal of Alternative and Complementary Medicine, 13, pp651-658.

Chiesa, A., \& Malinowski, P. (2011). Mindfulness based approaches: are they all the same? Journal of Clinical psychology, 67, pp404-424.

Chiesa, A., \& Serretti, A. (2009). Mindfulness-based stress reduction for stress management in healthy people: A review and meta-analysis. Journal of Alternative and Complementary Medicine, 15, pp593-600.

Christopher, J. C., Chrisman, J. A., Trotter-Mathison, M. J., Schure, M. B., Dahlen, P., \& Christopher, S. B. (2011). Perceptions of the long-term influence of mindfulness training on counselors and psychotherapists. Journal of Humanistic Psychology, 5, pp318-349.

Damasio, A. R. (2003). Looking for Spinoza: Joy, Sorrow, and the Feeling Brain: Harcourt.

Davidson, R. J. (2010). Empirical explorations of mindfulness: conceptual and methodological conundrums. Emotion, 10, pp8-11. 
Davis, D. M., \& Hayes, J. A. (2011). What are the benefits of mindfulness? A practice review of psychotherapy-related research. Psychotherapy, 48, pp198-208.

Ellenbogen, M. A., Schwartzman, A. E., Stewart, J., \& Walker, C. D. (2006). Automatic and effortful emotional information processing regulates different aspects of the stress response. Psychoneuroendocrinology, 31, pp373-387.

Fjorback, L. O., Arendt, M., Ørnbøl, E., Fink, P., \& Walach, H. (2011). Mindfulness Based Stress Reduction and Mindfulness Based Cognitive Therapy-a systematic review of randomized controlled trials. Acta Psychiatrica Scandinavica, 124, pp102-119.

Grossman, P. (2008). On measuring mindfulness in psychosomatic and psychological research. Journal of Psychosomatic Research, 64, pp405-408.

Harrington, N., \& Pickles, C. (2009). Mindfulness and Cognitive Behavioral Therapy: A rebuttal. Journal of Cognitive Psychotherapy, 23, pp333-335.

Hayes, S. C., Strosahl, K. D., \& Wilson, K. G. (1999). Acceptance and commitment therapy: An experiential approach to behaviour change. New York: Guilford Press.

Hofmann, S. G., Sawyer, A. T., Witt, A. A., \& Oh, D. (2010). The effect of mindfulness-based therapy on anxiety and depression: A meta-analytic review. Journal of Consulting and Clinical Psychology 78, pp169-183.

James, W. (1890). The Principles of Psychology: H. Holt.

Jha, A., Krompinger, J., \& Baime, M. J. (2007). Mindfulness training modifies subsystems of attention. Cognitive Affective and Behavioral Neuroscience, 7, pp109-119.

Kabat-Zinn, J. (1982). An out-patient program in behavioral medicine for chronic pain patients based on the practice of mindfulness meditation: theoretical considerations and preliminary results. General Hospital Psychiatry, 4, 33-47. 
Kabat-Zinn, J. (1994). Wherever You Go There You Are. New York: Hyperion.

Kabat-Zinn, J., Lipworth, L., Burney, R., \& Sellers, W. (1987). Four-Year follow-up of a meditation-based program for the self-regulation of chronic pain: Treatment outcomes and compliance. The Clinical Journal of Pain, 2, pp159-173.

Kabat-Zinn, J., Massion, A., Kristeller, J., Peterson, L., Fletcher, K., Pbert, L., . . Santorelli, S. (1992). Effectiveness of a meditation-based stress reduction program in the treatment of anxiety disorders. American Journal of Psychiatry, 149, pp936-943.

Keng, S. L., Smoski, M. J., \& Robins, C. J. (2011). Effects of mindfulness on psychological health: A review of empirical studies. Clinical Psychology Review, 31, pp1041-1056.

Kirschenbaum, D. S. (1987). Self-regulatory failure: A review with clinical implications. Clinical Psychology Review, 7, pp77-104.

Kuyken, W., Watkins, E., Holden, E., White, K., Taylor, R. S., Evans, A., . . Dalgleish, T. (2010). How does Mindfulness-based Cognitive Therapy work? Behaviour Research and Therapy, 48, pp1105-1112.

Langer, E. J., \& Moldoveanu, M. (2000). The construct of mindfulness. Journal of Social Issues, 56, pp1-9.

Linehan, M. M. (1993). Cognitive-behavioral treatment of borderline personality disorder. New York: Guilford Press.

Ludwig, D. S., \& Kabat-Zinn, J. (2008). Mindfulness in medicine. JAMA, 300, p1350.

Manzoni, G., Pagnini, F., Castelnuovo, G., \& Molinari, E. (2008). Relaxation training for anxiety: a ten-years systematic review with meta-analysis. BMC psychiatry, 8,41 .

Ortner, C. N. M., Kilner, S. J., \& Zelazo, P. D. (2007). Mindfulness meditation and reduced emotional interference on a cognitive task. Motivation and Emotion, 31, pp271-283. 
Patel, S., Carmody, J., \& Simpson, S. (2007). Adapting Mindfulness Based Stress Reduction for the treatment of obsessive compulsive disorder: A case report Cognitive and Behavioral Practice, 14, 375-380.

Pbert, L., Madison, J. M., Druker, S., Olendzki, N., Magner, R., Reed, G., . . Carmody, J. (2012). Effect of mindfulness training on asthma quality of life and lung function: a randomised controlled trial. Thorax, 67, pp769-776.

Safran, J. D., \& Segal, Z. V. (1990). Interpersonal process in cognitive therapy: New York: Basic Books.

Sanders, K. M. (2010). Mindfulness and psychotherapy. Focus, 8, pp19-24.

Sedlmeier, P., Eberth, J., Schwarz, M., Zimmermann, D., Haarig, F., Jaeger, S., \& Kunze, S. (2012). The psychological effects of meditation: A meta-analysis. Psychological Bulletin, 138, pp1139-1171.

Segal, Z. V., Williams, J. M. G., \& Teasdale, J. D. (2002). Mindfulness-based cognitive therapy for depression: A new approach to preventing relapse. New York: Guilford.

Shapiro, S. L., Carlson, L. E., Astin, J. A., \& Freedman, B. (2006). Mechanisms of mindfulness. Journal of Clinical Psychology, 62, pp373-386.

Slagter, H. A., Lutz, A., Greischar, L. L., Francis, A. D., Nieuwenhuis, S., Davis, J. M., \& Davidson, R. J. (2007). Mental training affects distribution of limited brain resources. PLoS Biology, 5, e138.

Teasdale, J. (1999). Metacognition, mindfulness and the modification of mood disorders. Clinical Psychology and Psychotherapy, 6, pp146-155. 
Teasdale, J. D., Moore, R. G., Hayhurst, H., Pope, M., Williams, S., \& Segal, Z. V. (2002). Metacognitive awareness and prevention of relapse in depression: Empirical evidence. Journal of Consulting and Clinical Psychology, 70, pp275-287.

Teasdale, J. D., Segal, Z., \& Williams, J. M. G. (1995). How does cognitive therapy prevent depressive relapse and why should attentional control (mindfulness) training help? Behaviour Research \& Therapy, 33, pp25-39.

Teasdale, J. D., Segal, Z. V., Williams, J. M. G., Ridgeway, V. A., Soulsby, J. M., \& Lau, M. A. (2000). Prevention of relapse/recurrence in major depression by mindfulness-based cognitive therapy. Journal of Consulting \& Clinical Psychology, 68, pp615-623.

Valentine, E. R., \& Sweet, P. L. G. (1999). Meditation and attention: A comparison of the effects of concentrative and mindfulness meditation on sustained attention. Mental Health, Religion \& Culture, 2, pp59-70.

Vøllestad, J., Nielsen, M. B., \& Nielsen, G. H. (2011). Mindfulness- and acceptance-based interventions for anxiety disorders: A systematic review and meta-analysis. British Journal of Clinical Psychology, 49, pp281-288.

Zeidan, F., Gordon, N. S., Merchant, J., \& Goolkasian, P. (2010). The effects of brief mindfulness meditation training on experimentally induced pain. Journal of Pain, 11, pp199-209. 
Figure 1: Automatic maintenance of distress when attention is unregulated or compelled

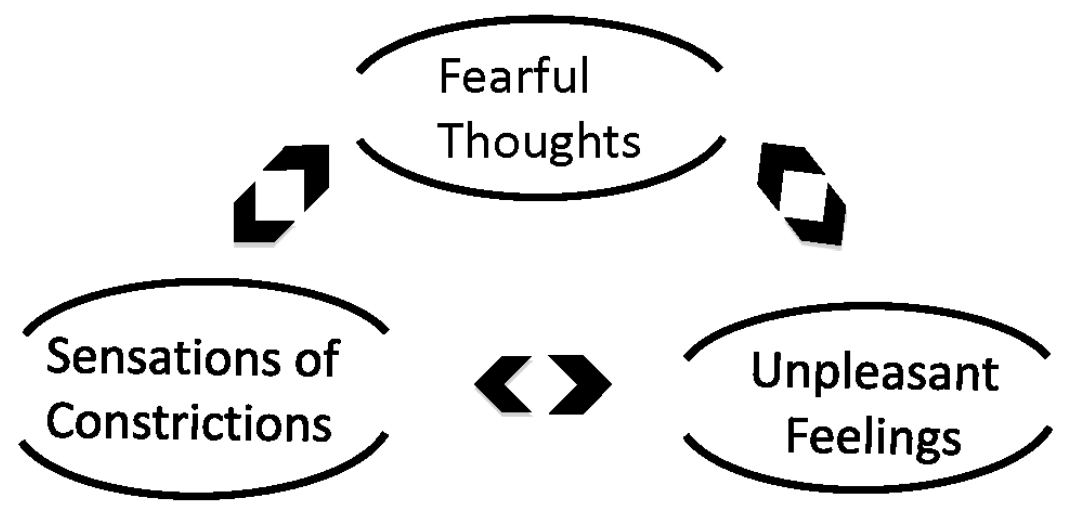

Patient reports:

'I feel tense/anxious/stressed/uptight all the time...' 
Figure 2: With mindfulness training patient recognizes...

* Components of the cycle maintaining distress

* Availability to attention of arousal-neutral sensations of breathing

* Redirecting attention to breath interrupts cycle maintaining distress

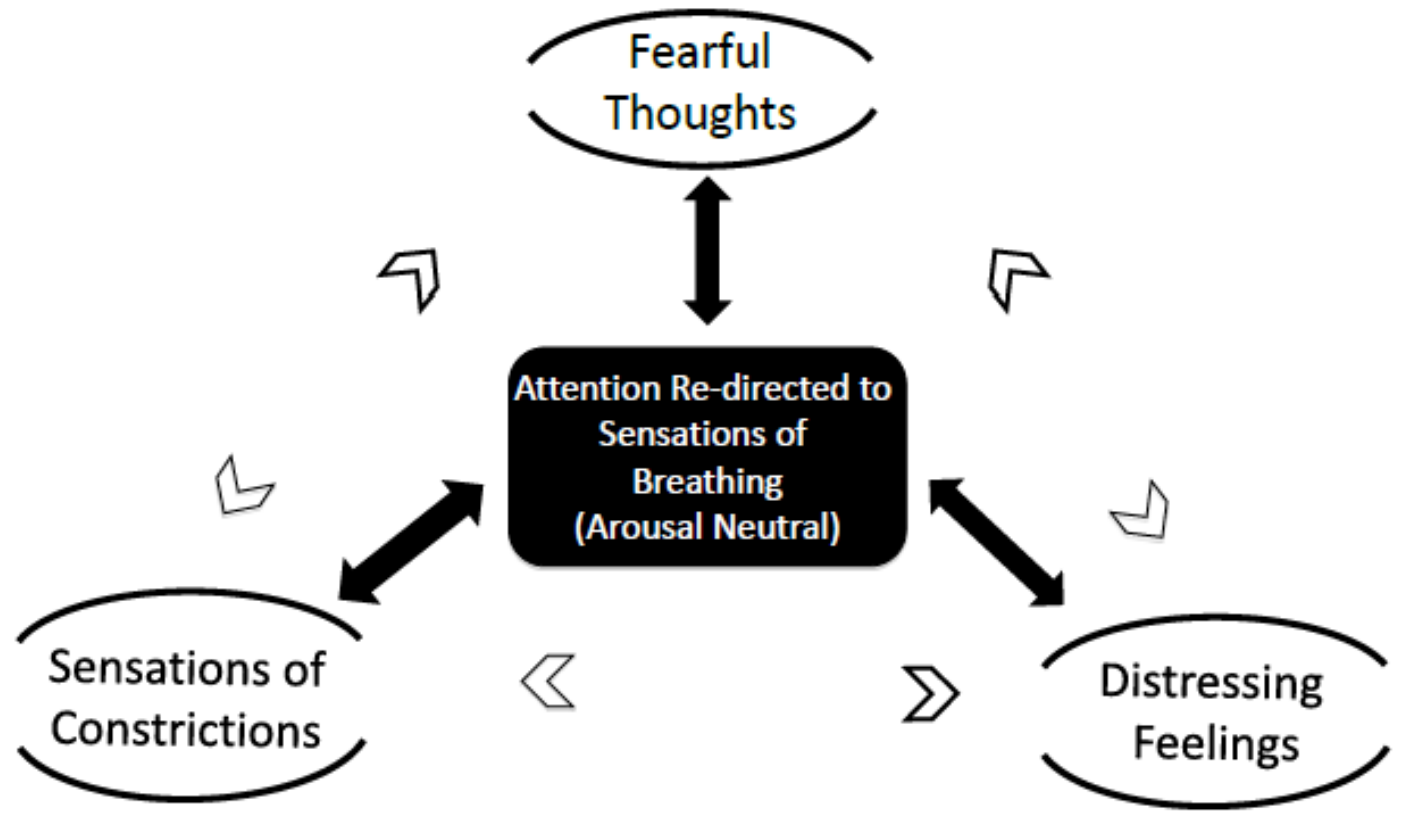


Figure 3: Reperceiving: Attentional/Perceptual shift from Thought's content... To the thought as an event in awareness

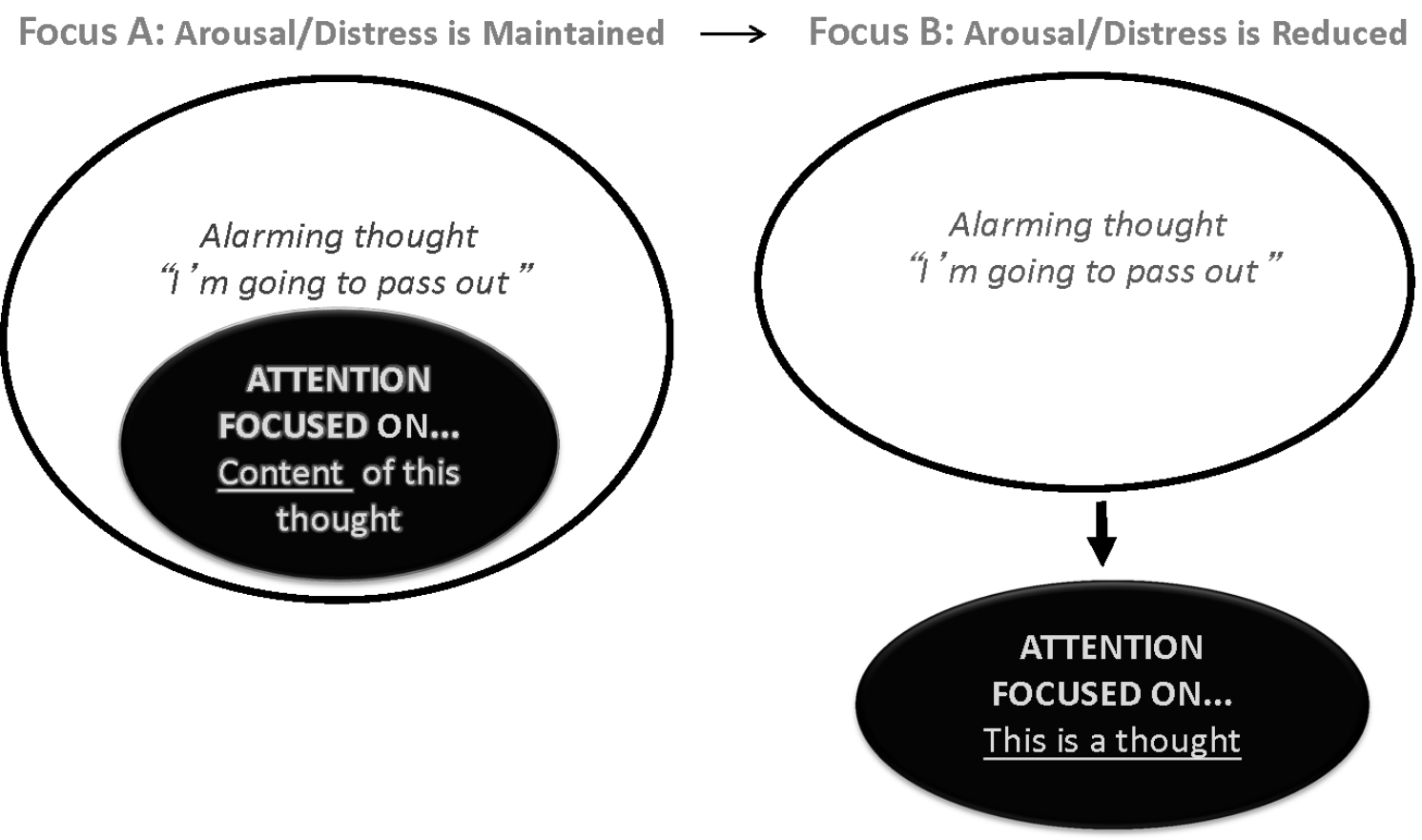

